\title{
Assessment and Comparison of Patient Safety Culture Among Health-Care Providers in Shenzhen Hospitals
}

This article was published in the following Dove Press journal: Risk Management and Healthcare Policy

\author{
Horng-Shuh Hao',* \\ Han Gao (D) ${ }^{1, *}$ \\ Ting $\mathrm{Li}^{2}$ \\ Dan Zhang'
}

'Institute for Hospital Management, Tsinghua Shenzhen International Graduate School, Tsinghua University, Shenzhen, People's Republic of China; ${ }^{2}$ Administrative Office, The Third People's Hospital of Shenzhen, Shenzhen, People's Republic of China

*These authors contributed equally to this work
Correspondence: Dan Zhang Institute for Hospital Management, Tsinghua Shenzhen International Graduate School, Tsinghua University, No. 2279 Lishui Road, Nanshan District, Shenzhen 5I8055, People's Republic of China

Tel $+86-|86-64555| 88$

Fax +86-755-26036425

Email zhang.dan@sz.tsinghua.edu.cn
Purpose: To investigate the health-care providers' perceptions of patient safety culture in Shenzhen hospitals and to compare 2019 with 2015 data.

Methods: This cross-sectional study adopted a questionnaire survey and targeted hospital staff fitting the sampling criteria (physicians, nurses, technicians, and managers). A total of 5490 staff from 13 Shenzhen hospitals were surveyed using the Hospital Survey on Patient Safety Culture (HSOPSC).

Results: The average positive response rates of this study were generally higher than the data from the 2018 Agency for Healthcare Research and Quality (AHRQ) survey and the 2015 HSOPSC Shenzhen survey. Bivariate and multivariate regression showed that respondents who had direct contact with patients were less likely to report high overall patient safety grade. The probability of high overall patient safety grade was rated higher by men than by women. Compared with nurses, the probability of high overall patient safety grade was higher for both physicians and technicians.

Conclusion: The overall results of the patient safety culture in Shenzhen hospitals were relatively good and have improved significantly in recent years, but some areas of weakness still need improvement. Our recommendations are to develop training programs for various positions, recruit more employees, provide management support, and establish a just culture to promote a strong patient safety culture. Regular assessment is also needed to provide valuable information to hospital leaders on areas requiring improvement and to evaluate the quality improvement plan that has been implemented.

Keywords: patient safety culture, HSOPSC, public hospital

\section{Introduction}

Patient safety is a critical component of the quality of healthcare. ${ }^{1}$ Over the past few decades, the importance of safety culture has been repeatedly emphasized to improve the quality and safety of health care ${ }^{2-5}$ because developing a culture of safety is believed to prevent adverse events or quickly correct mistakes before harm occurs. ${ }^{6}$

Safety culture is a sub-dimension of organizational culture. The concept of safety culture is usually divided into multiple subcultures, such as leadership, teamwork, evidence-based, communication, learning, just, and patient-centered. ${ }^{7}$ Organizations with a positive safety culture have communication based on mutual trust, shared perceptions about the importance of safety, confidence in the effectiveness of preventive measures, and support for the workforce. ${ }^{8}$ 
To transform culture, it is important to first understand and then challenge it. Culture assessment tools provide an avenue toward such an understanding. The tools take a managerial or staff perspective or combine elements of both. ${ }^{9}$ One of the benefits of measuring safety culture is that it provides a tangible indicator of the current status and of the progress over time of organizations and teams implementing improvements. ${ }^{10,11}$

There are numerous instruments for evaluating safety culture around the world; the more widely known tools are the Safety Attitude Questionnaire (SAQ), the Patient Safety Culture in Healthcare Organizations (PSCHO), and the Patient Safety Culture Survey Hospital (HSOPSC). ${ }^{8}$ HSOPSC of AHRQ is recognized as a de facto international survey because it has been widely used in over 45 countries. ${ }^{12}$ The various translated versions have acceptable psychometric properties. ${ }^{8}$ HSOPSC can be used to assess the patient safety culture at the individual, unit, and organizational levels or to make comparisons between different industries and countries. ${ }^{8}$ In addition to the questionnaire, AHRQ provides a 2018 database consists of data from 382,834 hospital respondents across 630 hospitals in the US participating in the HSOPSC survey. ${ }^{13}$ In 2015, the patient safety culture was surveyed in Shenzhen using the HSOPSC ${ }^{14}$ survey. Many previous studies have evaluated differences in patient safety culture between different professions, ${ }^{15,16}$ hospitals, or units ${ }^{5,17-19}$ in China. But the research populations are generally small; furthermore, managers and technicians are rarely investigated.

This study measured the perception of patient safety culture in China's tertiary public hospitals to discover the factors associated with high overall patient safety grade. We also compared some of the findings with existing data from the 2018 Agency for Healthcare Research and Quality (AHRQ) survey and the 2015 HSOPSC Shenzhen survey with the goal of understanding the changes and gaps.

\section{Methods}

\section{Sample}

This cross-sectional study was carried out in 13 tertiary public hospitals in Shenzhen, China, in May-June, 2019. The 13 hospitals were randomly selected for the survey. The participating hospitals represented a range of bed sizes and types of hospitals. A total of 5490 hospital staff including physicians, nurses, technicians (pharmacists, dieticians, physiotherapists, laboratory specialists, radiologists, and other technicians), and managers, were selected using stratified random sampling. The hospital staff was stratified based on the profession. Finally, 4583 questionnaires were completed yielding an overall response rate of $83.5 \%$.

Electronic or paper questionnaires were distributed by our research team members and coordinators after participating in a workshop in which the dos and don'ts and the instruments for the investigation were explained. The completed questionnaires were collected and delivered to the research team by the coordinators.

\section{Questionnaire}

The questionnaire was translated into Chinese by three students from the Institute for Hospital Management of Tsinghua University and then reviewed by four professional experts from the health care and patient safety fields. After back-translation into English by an independent translator, it was reviewed and revised by research coordinators from the 13 hospitals and by 4 experts with a patient safety, clinical, and English background. The questions in the background information section were adjusted to suit the habits of the Chinese.

The HSOPSC measures safety culture on 12 dimensions, including (1) communication openness, (2) feedback and communication about errors, (3) handoffs and transitions, (4) management support for patient safety, (5) nonpunitive response to errors, (6) organizational learning, (7) overall perception of patient safety, (8) staffing, (9) supervisor/manager expectations and actions promoting safety, (10) teamwork across units, (11) teamwork within units, and (12) frequency of events reported. Each dimension consisted of 3 or 4 questions, which were assessed on a 5-point Likert scale. One result variable (overall patient safety grade) scored from 1 to 5 ("failing" to "excellent") was used as an outcome variable. ${ }^{20}$ To get the average scores of each dimension, the items were linearly converted to a scale from 0 to 100 points. ${ }^{21}$ The average positive response rate refers to the combined percentage of respondents who answered "Strongly agree" or "Agree," or "Always" or "Most of the time", it was calculated for every participant based on the HSOPSC instructions.

The demographic characteristics included sex, age, professional experience, number of hours of work per week, direct interaction with patients, and staff position.

In this study, Cronbach's $\alpha$ values of the dimensions varied between 0.44 and 0.89 for the 12 dimensions (Table 1), while Cronbach's $\alpha$ values for the AHRQ data ranged from 0.63 to $0.84 .^{22}$ Some Cronbach's $\alpha$ values in 
Table I Cronbach's $\alpha$ for the 12 Dimensions of the HSOPSC

\begin{tabular}{|l|l|}
\hline Patient Safety Culture Dimensions & Cronbach's $\boldsymbol{\alpha}$ \\
\hline Communication openness & 0.47 \\
Feedback and communication about errors & 0.79 \\
Handoffs and transitions & 0.83 \\
Management support for patient safety & 0.63 \\
Nonpunitive response to errors & 0.50 \\
Organizational learning & 0.72 \\
Overall perception of patient safety & 0.45 \\
Staffing & 0.44 \\
Supervisor/manager expectations and actions & 0.69 \\
promoting safety & \\
Teamwork across units & 0.69 \\
Teamwork within units & 0.89 \\
Frequency of events reported & 0.89 \\
\hline
\end{tabular}

this study were low, which may have been caused by cultural differences. But we decided not to delete the dimensions with low internal consistency in order to compare our results with those from other studies.

\section{Ethics Approval and Consent to Participate}

This study has received ethics approval from Tsinghua Shenzhen International Graduate School Medical Ethics Committee. The questionnaire surveys were anonymous and voluntary, and written informed consent had been obtained from all study participants.

\section{Data Processing and Statistical Analysis}

This study used SPSS 20.0 for Windows to perform the data processing and statistical analyses. Negatively worded items in the HSOPSC were scored in reverse to ensure that positive answers would demonstrate higher scores. We calculated descriptive statistics for the demographic characteristics and the study variables as well as the percentage of positive responses for each dimension.

The differences in background characteristics and the reported patient safety culture among the different staff groups were examined by $\chi 2$ tests and one-way ANOVAs. Bonferroni-adjusted significance tests were used for pairwise comparisons.

The relationship between the explanatory variables $(6$ background variables and 12 dimensions of patient safety culture) and the outcome variable (overall patient safety grade) was examined by bivariate and multivariate logistic regression. The outcome variable was dichotomized into high ("excellent" and "very good") and low ("failing" to "acceptable") overall patient safety grade. Gender, age, staff position, professional experience, work time, and frequency of contact with patients were treated as dummy variables, and a forced-entry approach was adopted. The goodness-of-fit of the models was assessed by the HosmerLemeshow test $(\mathrm{P}>0.05)$. Multicollinearity in the multivariate logistic model was checked by the variance inflation factor (VIF < 3.09). The level of statistical significance was set as less than 0.05 .

\section{Results}

\section{Sample Characteristics}

Out of all 4583 respondents, $55 \%$ were nurses, $25 \%$ were physicians, $13 \%$ were technicians, and the remainder were managers (7\%). Most of the respondents (76\%) were female, were between the ages of 30 and 39 years ( $42 \%)$, had professional experience of more than 6 years $(33 \%)$, and worked 40 to 59 hours per week (71\%, Table 2). Moreover, about $87 \%$ of the respondents had direct interaction with patients.

\section{Average Scores of 12 Dimensions}

Among the 12 safety culture dimensions, the range of average scores was $58.3-86.6 \%$ (Table 2). The highestrated patient safety culture dimensions were "organizational learning" (mean, 86.6), "management support for patient safety" (mean, 84.9), and "handoffs and transitions" (mean, 84.3). The lowest-rated patient safety culture dimensions were "staffing" (mean, 58.3) and "overall perception of patient safety" (mean, 65.5).

There was a significant difference in the profession across multiple dimensions except for "management support for patient safety" and "teamwork within units". Managers scored the highest patient safety culture in all dimensions except for "communication openness," "handoffs and transitions," "nonpunitive response to errors," and "organizational learning” (Table 2).

\section{Average Positive Response Rate}

The strength areas of the safety culture (positive response rate $>75.0 \%$ ) were "organizational learning" (87.2\%), "teamwork within units" (86.9\%), "feedback and communication about errors" (86.7\%), and "supervisor/manager expectations and actions promoting safety" (78.2\%). The two lowest positive response rates were for "nonpunitive response to errors" (35.8\%) and "staffing" (37.6\%), which need improvement (scoring below 50\%). 
Table 2 Demographic Characteristic of Respondents and the Average Scores of Dimensions in HSOPSC

\begin{tabular}{|c|c|c|c|c|c|c|c|}
\hline Respondent Characteristics & $\begin{array}{l}\text { All Participants } \\
(\mathrm{N}=4583)\end{array}$ & $\begin{array}{l}\text { Physicians } \\
(n=1156)\end{array}$ & $\begin{array}{l}\text { Nurses } \\
(n=2526)\end{array}$ & $\begin{array}{l}\text { Technicians } \\
(n=576)\end{array}$ & $\begin{array}{l}\text { Managers } \\
(n=325)\end{array}$ & $p$ & $\begin{array}{l}\text { Post Hoc } \\
\text { (Bonferroni } \\
\text { Corrected)* }\end{array}$ \\
\hline $\begin{array}{l}\text { Sex, } \mathbf{n}(\%) \\
\text { Male } \\
\text { Female }\end{array}$ & $\begin{array}{l}1098(24.0) \\
3485(76.0)\end{array}$ & $\begin{array}{l}549(47.5) \\
607(52.5)\end{array}$ & $\begin{array}{l}180(7.1) \\
2346(92.9)\end{array}$ & $\begin{array}{l}260(45.1) \\
316(54.9)\end{array}$ & $\begin{array}{l}109(33.5) \\
216(66.5)\end{array}$ & $<0.001$ & \\
\hline $\begin{array}{l}\text { Age, } \mathbf{n}(\%), y \\
\quad<30 \\
30-39 \\
>39\end{array}$ & $\begin{array}{l}1623(35.4) \\
1941(42.4) \\
1019(22.2)\end{array}$ & $\begin{array}{l}179(15.5) \\
592(51.2) \\
385(33.3)\end{array}$ & $\begin{array}{l}1179(46.7) \\
969(38.3) \\
378(15.0)\end{array}$ & $\begin{array}{l}159(27.6) \\
255(44.3) \\
162(28.1)\end{array}$ & $\begin{array}{l}106(32.6) \\
125(38.5) \\
94(28.9)\end{array}$ & $<0.001$ & \\
\hline $\begin{array}{l}\text { Professional experience, } \boldsymbol{n} \text { (\%), } \boldsymbol{y} \\
<1 \\
1-2 \\
3-4 \\
5-6 \\
>6\end{array}$ & $\begin{array}{l}630(13.7) \\
1233(26.9) \\
716(15.6) \\
495(10.8) \\
1509(32.9)\end{array}$ & $\begin{array}{l}164(14.2) \\
299(25.9) \\
181(15.7) \\
113(9.8) \\
399(34.5)\end{array}$ & $\begin{array}{l}348(13.8) \\
696(27.6) \\
362(14.3) \\
297(11.8) \\
823(32.6)\end{array}$ & $\begin{array}{l}71(12.3) \\
125(21.7) \\
101(17.5) \\
54(9.4) \\
225(39.1)\end{array}$ & $\begin{array}{l}47(14.5) \\
114(34.8) \\
72(22.2) \\
31(9.5) \\
62(19.1)\end{array}$ & $<0.001$ & \\
\hline $\begin{array}{l}\text { Weekly work time, } \mathbf{n}(\%), \mathbf{h} \\
<40 \\
40-59 \\
>59\end{array}$ & $\begin{array}{l}828(18.1) \\
3237(70.6) \\
518(11.3)\end{array}$ & $\begin{array}{l}133(11.5) \\
671(58.0) \\
352(30.4)\end{array}$ & $\begin{array}{l}466(18.4) \\
1933(76.5) \\
127(5.0)\end{array}$ & $\begin{array}{l}159(27.6) \\
397(68.9) \\
20(3.5)\end{array}$ & $\begin{array}{l}70(21.5) \\
236(72.6) \\
19(5.8)\end{array}$ & $<0.001$ & \\
\hline $\begin{array}{l}\text { Contact with patients, } \mathbf{n}(\%) \\
\text { Yes } \\
\text { No }\end{array}$ & $\begin{array}{l}3971(86.6) \\
612(13.4)\end{array}$ & $\begin{array}{l}1115(96.5) \\
41(3.5)\end{array}$ & $\begin{array}{l}2441(96.6) \\
85(3.4)\end{array}$ & $\begin{array}{l}325(56.4) \\
25 I(43.6)\end{array}$ & $\begin{array}{l}90(27.7) \\
235(72.3)\end{array}$ & $<0.001$ & \\
\hline \multicolumn{8}{|l|}{$\begin{array}{l}\text { Patient safety culture dimensions, } \\
\text { mean (SD) }\end{array}$} \\
\hline $\begin{array}{l}\text { Communication openness } \\
\text { Feedback and communication about }\end{array}$ & $\begin{array}{l}80.3(18.4) \\
73.8(12.7)\end{array}$ & $\begin{array}{l}80.4(17.6) \\
72.8(13.4)\end{array}$ & $\begin{array}{l}81.3(18.2) \\
73.8(12.5)\end{array}$ & $\begin{array}{l}76.5(19.6) \\
74.7(12.1)\end{array}$ & $\begin{array}{l}78.3(19.9) \\
76.5(12.8)\end{array}$ & $\begin{array}{l}<0.001 \\
<0.001\end{array}$ & $\begin{array}{l}\mathrm{BD} \\
\mathrm{BCE}\end{array}$ \\
\hline $\begin{array}{l}\text { errors } \\
\text { Handoffs and transitions } \\
\text { Management support for patient safety }\end{array}$ & $\begin{array}{l}84.3(12.4) \\
84.9(13.9)\end{array}$ & $\begin{array}{l}84.0(12.4) \\
85.2(13.8)\end{array}$ & $\begin{array}{l}84.7(12.6) \\
84.9(14.0)\end{array}$ & $\begin{array}{l}83.5(11.5) \\
84.2(13.8)\end{array}$ & $\begin{array}{l}83.1(12.4) \\
85.7(14.3)\end{array}$ & $\begin{array}{l}0.03 \\
0.40\end{array}$ & \\
\hline Nonpunitive response to errors & $76.1(14.2)$ & $76.2(14.4)$ & $76.5(13.8)$ & $74.4(14.8)$ & $75.6(15.3)$ & 0.01 & $\mathrm{D}$ \\
\hline Organizational learning & $86.6(14.0)$ & $84.6(14.2)$ & $88.6(13.0)$ & $84.1(15.3)$ & $83.2(15.7)$ & $<0.001$ & $\mathrm{ADE}$ \\
\hline Overall perception of patient safety & $65.5(13.1)$ & $64.1(12.5)$ & $66.2(13.4)$ & $64.6(12.5)$ & $66.7(13.8)$ & $<0.001$ & $A C$ \\
\hline Staffing & $58.3(14.7)$ & $56.1(14.4)$ & $59.3(15.0)$ & $57.9(14.3)$ & $59.5(14.1)$ & $<0.001$ & $A C$ \\
\hline $\begin{array}{l}\text { Supervisor/manager expectations and } \\
\text { actions promoting safety }\end{array}$ & $77.7(14.3)$ & $75.9(15.0)$ & $78.0(14.0)$ & $78.2(14.1)$ & $80.6(13.7)$ & $<0.001$ & $\mathrm{ABCE}$ \\
\hline Teamwork across units & $73.6(13.8)$ & $72.6(13.9)$ & $73.9(13.7)$ & $73.5(13.7)$ & $75.1(13.8)$ & 0.007 & $A C$ \\
\hline Teamwork within units & $70.1(16.8)$ & $69.8(17.0)$ & $70.0(16.8)$ & $69.6(16.0)$ & $71.9(16.9)$ & 0.20 & \\
\hline Frequency of events reported & $79.7(13.7)$ & $78.7(13.9)$ & $80.1(13.7)$ & $79.3(13.9)$ & $80.5(13.2)$ & 0.02 & A \\
\hline Overall patient safety grade, mean (SD) & $3.9(0.9)$ & $3.9(1.0)$ & $3.8(0.9)$ & $4.0(0.9)$ & $4.0(1.0)$ & $<0.001$ & $\mathrm{BD}$ \\
\hline
\end{tabular}

Notes: *Significant differences between staff groups are marked with the following: A. physicians/nurses; B. physicians/technicians; C. physicians/managers; D. nurses/ technicians; E. nurses/managers; F. technicians/managers.

The average positive response rates for Shenzhen were generally higher than those for the AHRQ data, ${ }^{13}$ except for "nonpunitive response to errors," "staffing," "overall perception of patient safety," and "supervisor/manager expectations and actions promoting safety (Table 3, Figure 1)."

\section{Overall Patient Safety Grade}

The mean rating for overall patient safety was 3.9 for all participants, but the rating differed significantly between the staff positions $(\mathrm{P}<0.001)$. Specifically, technicians scored patient safety significantly higher than nurses and physicians (Table 2).

\section{Factors Associated with an Overall Patient Safety Grade}

The bivariate analysis showed that all 12 dimensions of patient safety culture were significantly associated with 
Table 3 Average Positive Response Rate for the HSOPSC Results for Shenzhen and AHRQ Data

\begin{tabular}{|c|c|c|c|}
\hline \multirow{2}{*}{$\begin{array}{l}\text { Patient Safety Culture } \\
\text { Dimensions }\end{array}$} & \multicolumn{3}{|c|}{ Average Response Rate (\%) } \\
\hline & $\begin{array}{l}\text { AHRQ } \\
(2018)\end{array}$ & $\begin{array}{l}\text { Shenzhen } \\
(20 I 5)\end{array}$ & $\begin{array}{l}\text { Shenzhen } \\
(2019)\end{array}$ \\
\hline Communication openness & $66 \%$ & $60.0 \%$ & $67.2 \%$ \\
\hline $\begin{array}{l}\text { Feedback and communication } \\
\text { about errors }\end{array}$ & $69 \%$ & $77.6 \%$ & $86.7 \%$ \\
\hline Handoffs and transitions & $48 \%$ & $51.2 \%$ & $57.2 \%$ \\
\hline $\begin{array}{l}\text { Management support for } \\
\text { patient safety }\end{array}$ & $72 \%$ & $72.7 \%$ & $72.5 \%$ \\
\hline $\begin{array}{l}\text { Nonpunitive response to } \\
\text { errors }\end{array}$ & $47 \%$ & $33.6 \%$ & $35.8 \%$ \\
\hline Organizational learning & $72 \%$ & $81.1 \%$ & $87.2 \%$ \\
\hline $\begin{array}{l}\text { Overall perception of patient } \\
\text { safety }\end{array}$ & $66 \%$ & $66.5 \%$ & $64.2 \%$ \\
\hline Staffing & $53 \%$ & $35.7 \%$ & $37.6 \%$ \\
\hline $\begin{array}{l}\text { Supervisor/manager } \\
\text { expectations and actions } \\
\text { promoting safety }\end{array}$ & $80 \%$ & $72.8 \%$ & $78.2 \%$ \\
\hline Teamwork across units & $62 \%$ & $58.6 \%$ & $63.7 \%$ \\
\hline Teamwork within units & $82 \%$ & $83.9 \%$ & $86.9 \%$ \\
\hline Frequency of events reported & $67 \%$ & $65.2 \%$ & $72.2 \%$ \\
\hline
\end{tabular}

overall patient safety grade (Table 4). A higher level of patient safety culture implies an increased probability for high overall patient safety grade. Higher age, males, technicians, and no direct interaction with patients were also associated with higher assessments of overall patient safety grade. Professional experience and work time were not significantly associated with overall patient safety grade.

Like the previous bivariate analysis, the findings for the multivariate analysis indicated that all the patient safety culture dimensions, except "handoffs and transitions," "nonpunitive response to errors," and "overall perception of patient safety," were significantly associated with overall patient safety grade. Moreover, the higher the patient safety culture score, the higher the probability of individual patient safety. Males and technicians were still associated with high overall patient safety grade. But no such association was shown for managers. In addition, age was no longer significantly associated with overall patient safety grade. Professional experience and work time were still not associated with overall patient safety grade (Table 4).

\section{Discussion}

In our study, we were able to explore safety culture issues from different perspectives along with the relationship between the explanatory variables (6 background variables and 12 dimensions of patient safety culture) and overall patient safety grade. Trending results were presented by comparing the 2015 and 2019 survey data, which were collected from the same hospitals. This study also identified areas of strengths and weaknesses, particularly in comparison to US AHRQ data.

The average positive response rates for Shenzhen (2019) were generally higher than the survey data four years ago. Across the 12 dimensions, "feedback and communication about errors" had the largest increase (9\%). "Communication openness" and "frequency of events reported" increased by 7\%. The reasons are very complicated. A possible explanation is that in September, 2016, the National Health and Family Planning Commission adopted the "Medical Quality Management Measures," which is the first medical quality regulation in mainland China, setting higher requirements for the quality and safety of medical institutions. ${ }^{23}$ In addition, many hospitals in Shenzhen use medical quality management tools for continuous quality improvement, such as root cause analysis (RCA), healthcare failure mode and effect analysis (HFMEA), and quality control circle (QCC). Our previous study found that QCC could play an active role in enhancing patient safety culture. ${ }^{24}$ It is also worth noting that Shenzhen established the Public Hospital Management Center separate from the Health Bureau in 2013. This center is responsible for operations and state asset management. The separation of management and surveillance was an attempt to break the pattern of self-serving interests in public hospitals and reform the management system. ${ }^{25}$ With this approach, there are fewer hierarchical and bureaucratic requirements and a more continuous effort to create a positive safety culture. Some studies have shown that hospitals with fewer hierarchical and bureaucratic requirements have better overall scores. ${ }^{26,27}$

It is also worth noting that the scores of "management support for patient safety" and "overall perception of patient safety" decreased slightly over the past four years. This may indicate that the interventions in the past few years may not have resulted in much attention being paid to patient safety culture education, training, and management support. Another possible explanation could be that hospital personnel have a different definition or mental perception of what constitutes patient safety than they did 4 years ago. The emphasis on patient safety may well have altered the hospital staff members' perceptions about what constitutes "safety." 


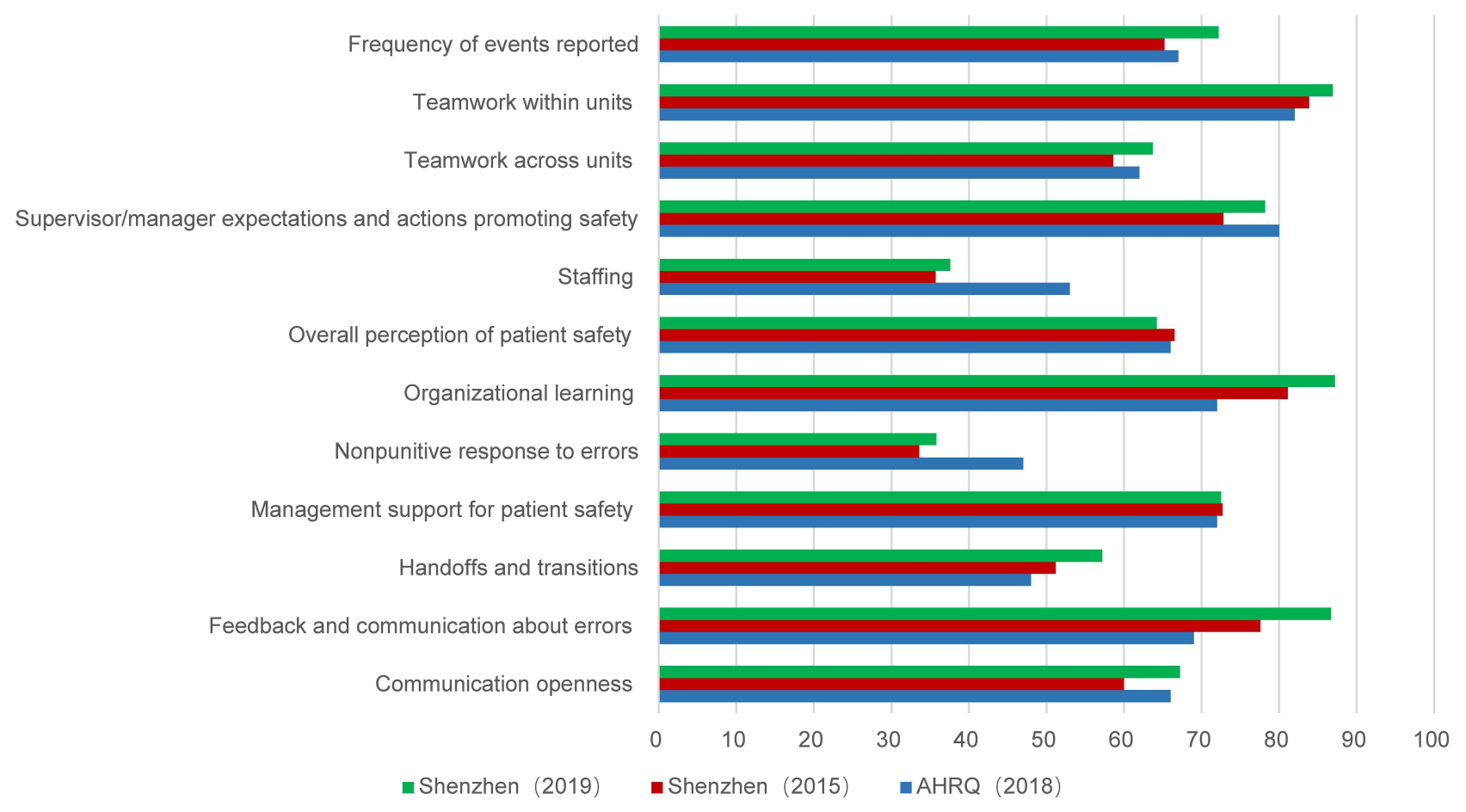

Figure I Comparison of the average positive response rate for the HSOPSC results from Shenzhen and AHRQ data.

The results on "communication openness," "feedback and communication about errors," and "frequency of events reported" were higher than the AHRQ (2018) and Shenzhen (2015) data. But this is logically inconsistent with the "nonpunitive response to errors" and "staffing," which showed lower positive response rates. This shows that, although the hospitals in Shenzhen formed an initial mechanism for handling adverse events, they still use punitive measures to deal with adverse events and have not yet sought out systemic risk factors. This finding is consistent with several other studies which indicate that an accusatory culture may still be common in Chinese hospitals. $5,15,18,28$

The findings show that "organizational learning," "teamwork within units," "feedback and communication about errors," and "supervisor/manager expectations and actions promoting safety" were the areas of strength, whereas Shenzhen (2015) studies found that the positive response rate for "supervisor/manager expectations and actions promoting safety" was not higher than $75.0 \%$. This implies that in recent years the managers of Shenzhen hospitals have paid more attention to patient safety issues by providing enough resources to support patient safety matters, maintaining open communication, and making continuous improvements. Learning, open communication, teamwork, and management engagement, and support are recognized as key aspects of patient safety culture. . $^{79,30}$

In our study, the lowest positive response rates were for "nonpunitive response to errors" (35.8\%), which shows similarities with many research results around the world. ${ }^{31-34}$ Respondents tended to believe that making or reporting mistakes is not good for them and will be kept in their files. This is because the culture of punishment and blame is still very common in the Chinese medical system. ${ }^{35}$ But in 1999 the Institute of Medicine pointed out that most errors in health care are caused by the system, not by individuals. ${ }^{2}$ Studies have shown that punitive responses to errors are the main obstacle for disclosure of errors once they are identified. ${ }^{36}$ To establish a just culture $^{7}$ that recognizes errors as system failures rather than individual failures and encourages the staff to report events without fear of blame is essential for better error identification and continuous improvements.

The respondents reported under-staffing as another area with the most potential for improvement, with scores much lower than the US data. According to OECD (2020) (latest data period 2015-2018), there were 2.7 nurses per 1000 inhabitants in China and 11.7 nurses per 1000 inhabitants in the United States. ${ }^{37}$ Thus, it is natural to find worse results on staffing compared with those from the United States. Some studies have shown a strong 
Table 4 Bivariate and Multivariate Logistic Regression Models with High Overall Patient Safety Grade as a Response Variable

\begin{tabular}{|c|c|c|c|c|c|c|}
\hline \multirow[t]{2}{*}{ Explanatory Variables } & \multicolumn{3}{|c|}{ Bivariate Model } & \multicolumn{3}{|c|}{ Multivariate Model } \\
\hline & OR & $95 \% \mathrm{Cl}$ & $\mathbf{P}$ & OR & $95 \% \mathrm{Cl}$ & $\mathbf{P}$ \\
\hline \multicolumn{7}{|l|}{ Patient safety culture dimensions, mean (SD) } \\
\hline Communication openness & 1.03 & $1.02-1.03$ & $<0.001$ & 1.01 & $1.01-1.02$ & $<0.001$ \\
\hline Feedback and communication about errors & 1.08 & $1.08-1.09$ & $<0.001$ & 1.03 & $1.03-1.04$ & $<0.001$ \\
\hline Handoffs and transitions & 1.06 & $1.05-1.06$ & $<0.001$ & 1.00 & $0.99-1.01$ & 0.502 \\
\hline Management support for patient safety & 1.05 & $1.05-1.06$ & $<0.001$ & 1.01 & $1.01-1.02$ & 0.001 \\
\hline Nonpunitive response to errors & 1.06 & $1.05-1.06$ & $<0.001$ & 1.01 & $1.00-1.01$ & 0.12 \\
\hline Organizational learning & 1.05 & $1.05-1.06$ & $<0.001$ & 1.01 & $1.01-1.02$ & $<0.001$ \\
\hline Overall perception of patient safety & 1.04 & $1.04-1.05$ & $<0.001$ & 1.00 & $0.99-1.01$ & 0.91 \\
\hline Staffing & 1.04 & $1.03-1.04$ & $<0.001$ & 1.02 & $1.01-1.02$ & $<0.001$ \\
\hline Supervisor/manager expectations and actions promoting safety & 1.07 & $1.06-1.08$ & $<0.001$ & 1.02 & $1.01-1.02$ & $<0.001$ \\
\hline Teamwork across units & 1.08 & $1.07-1.08$ & $<0.001$ & 1.02 & $1.01-1.03$ & $<0.001$ \\
\hline Teamwork within units & 1.05 & $1.04-1.05$ & $<0.001$ & 1.01 & $1.01-1.02$ & $<0.001$ \\
\hline Frequency of events reported & 1.07 & $1.06-1.07$ & $<0.001$ & 1.01 & $1.00-1.02$ & 0.006 \\
\hline \multicolumn{7}{|l|}{ Sex } \\
\hline \multicolumn{7}{|l|}{ Male (reference) } \\
\hline Female & 0.85 & $0.73-0.98$ & 0.03 & 0.68 & $0.56-0.83$ & $<0.001$ \\
\hline \multicolumn{7}{|l|}{ Age, y } \\
\hline$<30$ & 0.75 & $0.63-0.90$ & 0.001 & 0.80 & $0.62-1.03$ & 0.08 \\
\hline $30-39$ & 0.78 & $0.66-0.92$ & 0.003 & 0.88 & $0.7 \mid-1.08$ & 0.21 \\
\hline \multicolumn{7}{|l|}{$>39$ (reference) } \\
\hline \multicolumn{7}{|l|}{ Position } \\
\hline Physicians & 1.26 & $1.08-1.46$ & 0.003 & 1.38 & $|| 1-1.7 \mid$. & 0.004 \\
\hline \multicolumn{7}{|l|}{ Nurses(reference) } \\
\hline Technicians & 1.50 & $1.22-1.84$ & $<0.001$ & 1.56 & $1.18-2.06$ & 0.002 \\
\hline Managers & 1.35 & $1.04-1.75$ & 0.02 & 1.05 & $0.72-1.52$ & 0.80 \\
\hline \multicolumn{7}{|l|}{ Professional experience, $y$} \\
\hline \multicolumn{7}{|l|}{$<1$ (reference) } \\
\hline $1-2$ & 0.85 & $0.69-1.06$ & 0.14 & 0.92 & $0.72-1.18$ & 0.52 \\
\hline $3-4$ & 0.87 & $0.69-1.10$ & 0.24 & 1.06 & $0.80-1.4 \mid$ & 0.67 \\
\hline $5-6$ & 0.78 & $0.6 \mathrm{I}-1.0 \mathrm{I}$ & 0.06 & 1.03 & $0.75-|.4|$ & 0.85 \\
\hline$>6$ & 0.85 & $0.69-1.04$ & 0.11 & 0.98 & $0.74-1.29$ & 0.87 \\
\hline \multicolumn{7}{|l|}{ Weekly work time, h } \\
\hline$<40$ & 1.15 & $0.91-1.46$ & 0.25 & 0.93 & $0.69-1.25$ & 0.62 \\
\hline $40-59$ & 1.09 & $0.89-1.33$ & 0.40 & 0.99 & $0.77-1.27$ & 0.91 \\
\hline \multicolumn{7}{|l|}{$>59$ (reference) } \\
\hline \multicolumn{7}{|l|}{ Contact with patients } \\
\hline \multicolumn{7}{|l|}{ Yes(reference) } \\
\hline No & 1.34 & $1.10-1.62$ & 0.003 & $\mathrm{I} .40$ & $1.11-1.76$ & 0.004 \\
\hline
\end{tabular}

Abbreviations: $\mathrm{Cl}$, confidence interval; OR, odds ratio.

connection between staffing and patient safety, and low staffing may have a catastrophic impact on patient outcomes. ${ }^{38,39}$ The bivariate and multivariate regressions showed that respondents who had direct contact with patients were less likely to report high overall patient safety grade. A possible reason is that staff who care for patients are more stressed and prone to errors due to insufficient staffing.

The results showed that managers scored the highest patient safety culture in all dimensions except for "communication openness," "handoffs and transitions," "nonpunitive response to errors," and "organizational learning," 
a finding which has also been reported previously. ${ }^{13,21}$ But in terms of the mean rating for overall patient safety grade, technicians scored significantly higher than nurses and physicians. A Norwegian study found the same result. ${ }^{40}$ Nurses scored the lowest overall patient safety grade. The bivariate regression showed that technicians were more likely to report higher overall patient safety grade than the 3 professional categories. The multivariate regression revealed similar results, except that managers were no longer significantly associated with high overall patient safety grade. The possible reasons for the above findings are as follows: First, physicians and nurses have contact with patients more frequently than technicians and managers, and they are usually overloaded and suffer from stress due to under-staffing, all of which may affect the quality and patient outcomes. ${ }^{41,42}$ Overloaded staff tend to report a worse patient safety culture. ${ }^{43}$ Second, the managers place more emphasis on patient safety education, related regulations, and assessment of patient safety culture than physicians and nurses. ${ }^{15}$ However, the reasons why technicians and men were more likely to report high overall patient safety grades need further investigation. It is worth noting that the survey conducted in Shenzhen in 2015 found that there were no significant differences between physicians, nurses, technicians, and managers, ${ }^{44}$ which is different from this survey. One possible explanation is that through four years of practice on patient safety culture matters, hospital staff's understanding of patient safety has been affected by their respective professions. This also confirms the necessity of continuous research on patient safety culture.

\section{Strengths and Limitations}

Our study has several strengths. First, this is one of the few large-scale studies assessing patient safety culture in China, the previous research populations were generally small. ${ }^{5,14,18,44}$ Second, the study encompassed physicians, nurses, technicians, and managers who represented different professional designations of hospital staff. However, other studies rarely investigated managers' perceptions. Third, we examined trends over time by comparing the 2015 and 2019 survey data. Despite these strengths, several limitations of this study should be noted. First, selfreported surveys are subject to bias that respondents are more likely to report what is socially acceptable or preferred. Second, this study included only tertiary public hospitals in Shenzhen, which may have introduced some bias and caused a lack of applicability to private hospitals and smaller hospitals. Third, our study investigated the views of only a few non-professionals such as housekeepers, but they may have an impact on patient safety issues, so future studies might consider this.

\section{Conclusion}

According to the survey data, the overall results of the patient safety culture in Shenzhen public hospitals were relatively good and had improved significantly in recent years, but there are still some areas of weakness that need to be improved. Our recommendations are to develop training programs for various positions, recruit more employees, provide management support, and establish a just culture to promote a strong patient safety culture. Finally, regular assessments are needed to provide valuable information to hospital leaders on areas requiring improvement and to evaluate the quality improvement plan that has been implemented.

\section{Funding}

This work was supported by Research Fund of Shenzhen Public Hospital Management Center [grant number 20199660001] and Young Teacher Research Fund of Graduate School at Shenzhen, Tsinghua University [grant number 20195720011]. This work was also a project of Shenzhen Key Research Base of Humanities and Social Sciences.

\section{Disclosure}

The authors report no conflicts of interest in this work.

\section{References}

1. Reis CT, Paiva SG, Sousa P. The patient safety culture: a systematic review by characteristics of hospital survey on patient safety culture dimensions. Int J Qual Health C. 2018;30(9):660-677. doi:10.1093/ intqhe/mzy080

2. Kohn LT, Corrigan J, Donaldson MS. To Err is Human: Building a Safer Health System. Vol. 6. Washington, DC: National academy press; 2000.

3. Leape LL. Institute of medicine medical error figures are not exaggerated. JAMA. 2000;284(1):95-97. doi:10.1001/jama.284.1.95

4. Ammouri AA, Tailakh AK, Muliira JK, Geethakrishnan R, Al Kindi SN. Patient safety culture among nurses. Int Nurs Rev. 2015;62(1):102-110. doi:10.1111/inr.12159

5. Nie Y, Mao X, Cui H, He S, Li J, Zhang M. Hospital survey on patient safety culture in China. BMC Health Serv Res. 2013;13(1):228. doi:10.1186/1472-6963-13-228

6. Leape LL, Woods DD, Hatlie MJ, Kizer KW, Schroeder SA, Lundberg GD. Promoting patient safety by preventing medical error. JAMA. 1998;280(16):1444-1447. doi:10.1001/jama.280.16.1444

7. Sammer CE, Lykens K, Singh KP, Mains DA, Lackan NA. What is patient safety culture? A review of the literature. J Nurs Scholarsh. 2010;42(2):156-165. doi:10.1111/j.1547-5069.2009.01330.x 
8. Health F. Evidence Scan: Measuring Safety Culture. Vol. 2020. 2011.

9. Nieva VF, Sorra J. Safety culture assessment: a tool for improving patient safety in healthcare organizations. Qual Saf Health Care. 2003;122:I17-I23.

10. Makary MA, Sexton JB, Freischlag JA, et al. Patient safety in surgery. Ann Surg. 2006;243(5):628. doi:10.1097/01 sla.0000216410.74062.0f

11. Pronovost PJ, Miller MR, Wachter RM. Tracking progress in patient safety: an elusive target. JAMA. 2006;296(6):696-699. doi:10.1001/ jama.296.6.696

12. Sorra JS, Battles J. Lessons from the AHRQ hospital survey on patient safety culture. Patient Saf Cult. 2018;263.

13. Famolaro T, Yount N, Hare R, et al. Hospital Survey on Patient Safety Culture 2018 User Database Report. 2018; Rockville, MD.

14. Li T, Hao H, Li Z, Yao L, Lin H, Zhang M. Application on hierarchical linear model in hospital survey of patient safety culture in tertiary public hospitals. Chin Hosp. 2019;23(1):27-29.

15. Zhao X, Liu W, Wang Y, Zhang L. Survey and analysis of patient safety culture in a county hospital. Fam Med Community Health. 2017;5(4):299-310. doi:10.15212/FMCH.2017.0137

16. Liao J, Sun C, Wang J, Chen W, Liao S. Current situation and influencing factors of patient safety culture among medical staffs in 4 hospitals of Shenzhen City. Chongqing Med. 2017;46 (13):1801-1803.

17. Wang M, Tao H. How does patient safety culture in the surgical departments compare to the rest of the county hospitals in Xiaogan City of China? Int J Environ Res Public Health. 2017;14(10):1123.

18. Liu C, Liu W, Wang Y, Zhang Z, Wang P. Patient safety culture in China: a case study in an outpatient setting in Beijing. BMJ Qual Saf. 2014;23(7):556-564. doi:10.1136/bmjqs-2013-002172

19. Wang M, Tao H, Fang H, et al. Patient safety culture in surgical departments versus other departments in county hospitals of Hubei province, China: a cross-sectional survey. Lancet. 2016;388:S71. doi:10.1016/S0140-6736(16)31998-5

20. Sorra JS, Dyer N. Multilevel psychometric properties of the AHRQ hospital survey on patient safety culture. BMC Health Serv Res. 2010;10(1):199. doi:10.1186/1472-6963-10-199

21. Danielsson M, Nilsen P, Rutberg H, Årestedt K. A national study of patient safety culture in hospitals in Sweden. J Patient Saf. 2019;15 (4):328-333. doi:10.1097/PTS.0000000000000369

22. Fleming M. Patient safety culture measurement and improvement: a "how to" guide. Healthc Q. 2005;8(SpecNo):14-19. doi:10.12927/ hcq.2005.17656

23. Darimont B, Margraf LW. Analysis of quality assurance in the hospital sector of the People's Republic of China. Qual Assur. 2018;2.

24. Zhang D, Liao M, Zhou Y, Liu T. Quality control circle: a tool for enhancing perceptions of patient safety culture among hospital staff in Chinese hospitals. Int $J$ Qual Health C. 2020;32(1):64-70. doi:10.1093/intqhe/mzz094

25. Zhang L, Li M, Ye F, Ding T, Kang P. An Investigation Report on Large Public Hospital Reforms in China. Springer; 2016.

26. El-Jardali F. The Impact of Hospital Rationalization and the Interrelationships Among Organizational Culture and Nursing Care Processes on Health Related Patient Outcomes. Carleton University; 2003.
27. El-Jardali F, Sheikh F, Garcia NA, Jamal D, Abdo A. Patient safety culture in a large teaching hospital in Riyadh: baseline assessment, comparative analysis and opportunities for improvement. BMC Health Serv Res. 2014;14(1):122. doi:10.1186/1472-6963-14-122

28. Chen I, Li H. Measuring patient safety culture in Taiwan using the hospital survey on patient safety culture (HSOPSC). BMC Health Serv Res. 2010;10(1):152. doi:10.1186/1472-6963-10-152

29. Waterson P. Patient Safety Culture: Theory, Methods and Application. CRC Press; 2018.

30. Feng XQ, Acord L, Cheng Y, Zeng JH, Song JP. The relationship between management safety commitment and patient safety culture. Int Nurs Rev. 2011;58(2):249-254. doi:10.1111/j.1466-7657.2011.00891.x

31. Ramos RR, Calidgid CC. Patient safety culture among nurses at a tertiary government hospital in the Philippines. Appl Nurs Res. 2018;44:67-75. doi:10.1016/j.apnr.2018.09.007

32. El-Jardali F, Jaafar M, Dimassi H, Jamal D, Hamdan R. The current state of patient safety culture in Lebanese hospitals: a study at baseline. Int J Qual Health C. 2010;22(5):386-395. doi:10.1093/ intqhe/mzq047

33. Güneş ÜY, Gürlek Ö, Sönmez M. A survey of the patient safety culture of hospital nurses in Turkey. Collegian. 2016;23(2):225-232. doi:10.1016/j.colegn.2015.02.005

34. Arabloo J, Rezapour A, Azar F, Safari H, Mobasheri Y. Measuring patient safety culture in iran using the hospital survey on patient safety culture (HSOPS): an exploration of survey reliability and validity. Int J Hosp Res. 2012;1.

35. Damayanti RA, Bachtiar A. Outcome of Patient Safety Culture Using the Hospital Survey on Patient Safety Culture (HSOPSC) in Asia: A Systematic Review with Meta Analysis. 2019.

36. Van Geest JBCD. An Educational Needs Assessment for Improving Patient Safety: Results of a National Study of Physicians and Nurses. White Paper Report 3. National Patient Safety Foundation; 2003.

37. OECD. Nurses (Indicator). Vol. 2020; 2020.

38. Zander B, Aiken LH, Busse R, Rafferty AM, Sermeus W, Bruynell L. The state of nursing in the European Union. EuroHealth. 2016;22 (1):4-8.

39. Aiken LH, Sloane DM, Bruyneel L, et al. Nurse staffing and education and hospital mortality in nine European countries: a retrospective observational study. Lancet. 2014;383(9931):1824-1830. doi:10.1016/S0140-6736(13)62631-8

40. Haugen AS, Søfteland E, Eide GE, Nortvedt MW, Aase K, Harthug S. Patient safety in surgical environments: cross-countries comparison of psychometric properties and results of the Norwegian version of the hospital survey on patient safety. BMC Health Serv Res. 2010;10(1):279. doi:10.1186/1472-6963-10-279

41. Sanderson J, Cook G. ABC of Patient Safety. UK: Blackwell; 2007:2.

42. Baldwin DC Jr, Daugherty SR, Tsai R, Scotti MJ Jr. A national survey of residents' self-reported work hours: thinking beyond specialty. Acad Med. 2003;78(11):1154-1163. doi:10.1097/00001888200311000-00018

43. Aiken LH, Sloane DM, Clarke S, et al. Importance of work environments on hospital outcomes in nine countries. Int J Qual Health C. 2011;23(4):357-364. doi:10.1093/intqhe/mzr022

44. Li T, Li Z, Hao H, et al. HSOPSC based questionnaire on patient safety culture in a tertiary public hospital. Chin Hosp. 2017;021 (009):29-32. 


\section{Publish your work in this journal}

Risk Management and Healthcare Policy is an international, peerreviewed, open access journal focusing on all aspects of public health, policy, and preventative measures to promote good health and improve morbidity and mortality in the population. The journal welcomes submitted papers covering original research, basic science, clinical \& epidemiological studies, reviews and evaluations, guidelines, expert opinion and commentary, case reports and extended reports. The manuscript management system is completely online and includes a very quick and fair peer-review system, which is all easy to use. Visit http://www.dovepress.com/testimonials.php to read real quotes from published authors. 